\title{
ESPECIALIZAÇÃO DE ENDODONTIA DA UEM: AVALIAÇÃO RADIOGRÁFICA DA QUALIDADE DOS TRATAMENTOS
}

Mônica Yuri Orita MISAWA, Ana Amélia Costa BRUNO, Nair Narumi Orita PAVAN

A divisão do tratamento endodôntico em fases distintas é uma prática comum. Contudo, atribuir diferentes graus de importância a cada fase é uma atitude a ser evitada; pois somente quando todas as fases são bem planejadas e executadas um resultado satisfatório pode ser alcançado. Além disso, é importante ressaltar o fato de que na obturação conseguimos avaliar o sucesso obtido nas fases anteriores do tratamento, sendo que uma obturação insatisfatória pode contribuir para o fracasso da terapia endodôntica. A proposta deste estudo foi analisar radiograficamente a qualidade dos tratamentos endodônticos realizados por alunos de pós-graduação do Curso de Especialização da UEM, no que se refere ao limite do preenchimento do canal radicular e da qualidade da condensação lateral. Foram verificadas 759 radiografias, pertencentes a 608 pacientes de ambos os gêneros e de diferentes faixas etárias. Os resultados encontrados revelaram que: 77,7\% dos canais radiculares estavam bem obturados e $92 \%$ dos canais radiculares estavam satisfatoriamente condensados.

Palavras-chave: tratamento endodôntico; avaliação radiográfica; obturação. 